NBER WORKING PAPER SERIES

CONSUMER DURABLES AND THE REAL INTEREST RATE

N. Gregory Mankiw

Working Paper No. 1148

NATIONAL BUREAU OF ECONOMIC RESEARCH

1050 Massachusetts Avenue

Cambridge MA 02138

June 1983

The research reported here is part of the NBER's research program in Economic Fluctuations. It was conducted while the author was a member of the research program at NBER. Any opinions expressed are those of the author and not those of the National Bureau of Economic Research or the Council of Economic Advisers. 


\section{Consumer Durables and the Real Interest Rate}

\section{Abstract}

One important channel through which real interest rates affect aggregate demand is consumer expenditure on durable goods. This paper examines empirically the link between interest rates and consumer durables. Solving for the decision rule relating income and interest rates to consumer demand is an intractable task. This paper avoids this problem by examining the first-order conditions necessary for maximization by the representative consumer. Structural parameters of the representative utility function are thus recovered. The estimated model suggests that expenditure on consumer durables is far more sensitive to changes in the interest rate than is expenditure on nondurables and services.

N. Gregory Mankiw

Council of Economic Advisers Old Executive Office Building

Washington, D.C. 20500 


\section{Introduction}

Restrictive monetary policy reduces aggregate demand by raising the real interest rate. Government spending crowds out private spending also by raising the interest rate; the more interest sensitive is private demand, the greater is the crowding out, and the lower is the multiplier. Consumer expenditure on durable goods is one important channel of these effects. The purpose of this paper is to examine empirically the linkage between interest rates and consumer durables.

There has been relatively little recent work on consumer durables. The studies that do exist largely ignore the effects of interest rates. In my 1982 paper, I examine the implications of the permanent income hypothesis for durable goods. Although the theory is soundly rejected, the test assumes a constant real interest rate. Bernanke's (1982) recent paper emphasizes the role of adjustment costs. He too rejects the permanent income hypothesis, yet he cannot solve his model allowing for a variable and uncertain real rate of return. The rejections reported in these papers are possibly due to unwarranted assumptions regarding the real interest rate. Indeed, expenditure on durables is often thought to be very interest sensitive. The model presented and estimated in this paper directly.measures the interest sensitivity of 
consumer expenditure both on durables and on nondurables and services.

Lucas (1976), in his now famous critique of econometric policy evaluation, cogently criticizes the use of a standard reduced form consumption function. A new approach, which began with Hall (1978), has evolved in an attempt to estimate structural parameters while avoiding the problems Lucas points out. Instead of estimating the decision rule relating income and interest rates to consumer demand, only the first-order conditions necessary for an optimum are examined. Grossman and Shiller (1981), Hall (1982), Hanson and Singleton (1983), Mankiw (1981), Runkle (1982), Shapiro (1983), Shiller (1982) and summers (1982) all use this approach to study consumption and asset returns in the case of nondurable goods. In my 1982 paper with Rotemberg and summers, we examine the intertemporal substitution in both consumption and labor supply. All these studies ignore durable goods. This paper therefore extends this new methodology to model the demand for consumer durables.

The estimated model suggests that expenditure on durables is far more sensitive to changes in the interest rate than is expenditure on nondurables and services. In particular, a temporary one percentage point increase in the real interest rate reduces the stock of durables by 3.4 percent, while it reduces the expenditure on nondurables and services by only .5 percent. Since the stock of durables is four times the annual flow, this one percentage point higher interest rate reduces annual expenditure on durables by 13.6 percent. 
Section II of this paper describes the model. Section III explains the model's implementation. In particular, it describes the estimation procedure and the use of the estimated parameters. Section IV describes the data, while section $V$ presents the results. Section VI is a brief conciusion: 
II. The Model

I assume that aggregate consumption behavior can be modeled as the optimizing decisions of a representative consumer. The consumer maximizes the following utility function.

(I) E $\sum_{t} \sum_{=0}^{\infty}(1+\gamma)^{-s}\left[U\left(C_{t+s}\right)+V\left(K_{t+s}\right)\right]^{\bullet}$

where $\quad E_{t}=$ expectation conditional on information available at time $t$

$\gamma=$ rate of subjective time preference;

C = consumption of nondurable goods;

$K$ = stock of durable goods providing services to the consumer;

$U$ = one-period utility from the nondurable goods:

$\mathrm{V}=$ one-period utility from the durable goods.

Various assumptions are implicit in this utility function. First, the objective function is additively separable through time. Although it has no theoretical basis, most previous work maintains this assumption, primarily since it facilitates the generation of empirically testable hypotheses. Second, nondurables and durables are additively separable in the utility function. In addition, by ignoring, the utility of leisure, I implicitly assume that leisure and consumption are additively separable. The main virtue of these postulates, which are also maintained in most previous work, is again parsimony. In my 1982 paper with Rotemberg and summers, we allow non-separability between consumption and leisure. In that paper, no qualitative conclusions are altered, and no additional insights are gained, by relaxing 
this separability assumption. Throughout this study, I maintain the assumption of additive separability both through time and among nondurable consumption, durable consumption, and leisure.

I assume the consumer has access to some capital market. That is, he is not liquidity constrained. Let $i_{t}$ be the nominal interest rate at which he can, at the margin, borrow and lend. If $\tau$ is his marginal tax rate, $(1-i) i_{t}$ is his after tax nominal interest rate. The consumer can trade off present and future expenditure on nondurables and durables at this relative price.

Solving for the consumer's decision rule is an almost intractible task. The current levels of $C_{t}$ and $K_{t}$ depend upon the entire subjective distribution of all future interest rates, prices and incomes. Lucas (1976) correctly criticizes the derivation and use of standard consumption functions. These consumption functions insufficiently treat the formation of expectations. The estimated parameters are not invariant with respect to policy changes, and meaningful interpretation of the econometric results is difficult. This paper avoids this problem by examining the first-order conditions for an optimum, rather than the reduced form decision rule.

I examine two first-order conditions necessary for maximation of the utility function (1). Their derivation rests upon simple perturbation arguments. In particular, no feasible perturbation from an optimum should increase expected utility. The first-order effect of a small feasible perturbation is zero, just as an indifference curve is tangent to the budget constraint at a maximum. 
First, consider a reduction in current consumption of $d C_{t}$. Current utility is reduced by $U^{\prime}\left(C_{t}\right) d C_{t} \cdot$ Nominal spending is reduced by $P_{t}^{C} d C_{t}$. The consumer invests this extra saving and, in period $t+1$, has an extra $\left(1+(1-\tau) i_{t}\right) P_{t}^{c} d C_{t}$ to spend. The. extra consumption he purchases is $d_{t+1}=\left(1+(1-\tau) i_{t}\right) P_{t}^{c} d C_{t} / P_{t+1}^{c}$ The extra utility is $U^{\prime}\left(C_{t+1}\right) d C_{t+1}$. The total change in utility from this feasible perturbation, discounted at the rate subjective time preference $\gamma$, is the following.

(2) $-U^{\prime}\left(C_{t}\right) d C_{t}+(1+\gamma)^{-1} U^{\prime}\left(C_{t+1}\right)\left(1+(1-\tau) i_{t}\right) P_{t}^{c} d C_{t} / P_{t+1}^{c}$

This change must, at an optimum, have an expectation of zero. Thus, the following first-order condition is necessary.

$$
E_{t}\left[\frac{R_{t+1}^{1} U^{\prime}\left(C_{t+1}\right)}{(1+\gamma) U^{\prime}\left(C_{t}\right)}\right]=1
$$

where

(4) $R_{t+1}^{1}=\left(1+(1-\tau) i_{t}\right) P_{t}^{c} / P_{t+1}^{c}$

Previous studies--Grossman and Shiller (1981), Hall (1982),

Hanson and Singleton (1983), Mankiw, Rotemberg and Summers (1983), Runkle (1982), Shapiro (1982), Shiller (1982) and Summers (1982) --extensively examine condition (3).

second, consider a reduction in the current durables stock of $d K_{t}$. Current utility is reduced by $\mathrm{V}^{\prime}\left(\mathrm{K}_{t}\right) \mathrm{dK} \mathrm{K}_{t^{-}}$Nominal spending is reduced by $P_{t}^{k} d K_{t}$. In period $t+I_{r}$ the consumer has an extra $\left(1+(1-\tau) i_{t}\right) p_{t}^{k} d k_{t} \quad$ to spend. He spends it in two ways. He first purchases durables in order to restore the stock in period 
$t+1$. In the absence of this purchase, the stock is $(I-\delta) d k_{t}$ lower, where $\delta$ is the depreciation rate. Hence, he spends $(1-\delta) P_{t+1}^{k} d_{t}$ on durables. There is therefore no change in $\mathrm{K}_{t+1}$. The remainder of his extra expenditure is on nondurables. He buys $\mathrm{dc}_{\mathrm{t}+1}=\left(\left(1+(1-\tau) i_{t}\right) \mathrm{P}_{\mathrm{t}}^{\mathrm{k}}-(1-\delta) \mathrm{P}_{\mathrm{t}+1}^{\mathrm{k}}\right) \mathrm{dK}_{\mathrm{t}} / \mathrm{P}_{\mathrm{t}+1}^{\mathrm{c}}$. The change in utility is $U^{\prime}\left(C_{t+1}\right) d C_{t+1}$. The total change in utility from this feasible perturbation, discounted at the rate of subjective time preference $\gamma_{r}$ is the following.

(5) $-V^{\prime}\left(K_{t}\right) d K_{t}+(1+\gamma)^{-1}\left(\left(1+(1-\tau) i_{t}\right) P_{t}^{k}-(1-\delta) P_{t+1}^{k}\right) U^{\prime}\left(C_{t+1}\right) d K_{t} / P_{t+1}^{c}$

This change must, at an optimum, have an expectation of zero. The second first-order condition is the following.

(6) $E_{t}\left[\frac{R_{t+1}^{2} U^{\prime}\left(C_{t+1}\right)}{(1+\gamma) V^{\prime}\left(k_{t}\right)}\right]=1$

where

(7) $R_{t+1}^{2}=\left(\left(1+(1-\tau) i_{t}\right) P_{t}^{k}-(1-\delta) P_{t+1}^{k}\right) / P_{t+1}^{c}$

No study has examined condition (6). This equation allows us to examine the link between interest rates and consumption of both nondurables and durables.

The first-order condition (6) is based upon the somewhat unnatural comparison between the current stock of durables and next period's consumption of nondurables. Indeed, that the perturbation is so unnatural may explain why previous work on durables has typically not allowed a stochastic real interest rate. There are, of course, other more natural perturbations to consider. Yet these often produce first-order conditions with 
more than two terms. For example, suppose the representative consumer reduces current nondurable consumption $C_{t}$ and increases expenditure on durables. In this case, with exponential depreciation, all future stocks of aurables $K_{t}{ } K_{t+I}, \ldots$ are at least slightly altered. The resulting first-order condition therefore has an infinite number of terms. The virtue of equation (6) is that it is tractible, and that it allows the econometrician to estimate directly parameters of the underlying utility function.

It is useful to consider the two relative price variables $\mathrm{R}^{1}$ and $\mathrm{R}^{2}$. Although they may appear somewhat intricate, they are actually quite intuitive. They are approximately the following.

$$
\begin{aligned}
& \text { (4') } R^{1}=1+(1-\tau) i-\pi^{c} \\
& \left(7^{\prime}\right) R^{2}=\frac{\mathrm{P}^{\mathrm{k}}}{\mathrm{P}^{c}}\left[\delta+(1-\tau) i-\pi^{\mathrm{k}}\right]
\end{aligned}
$$

where $\pi^{c}$ and $\pi^{k}$ are the inflation rates for nondurables and durables, respectively. $R^{I}$ is simply one plus the real interest rate measured in terms of nondurable goods, which is the relative price of consumption today versus consumption tomorrow. In the certainty case, the first-order condition (3) equates this relative price to the marginal rate of substitution between consumption today and consumption tomorrow. The relative price $\mathrm{R}^{2}$ is the depreciation rate plus the real interest measured in terms of the durable good, all multiplied by the relative price of durables. Intuitively, it is the relative price of holding durables today versus consuming nondurables tomorrow. Under certainty, the firstorder condition (6) equates this relative price to the relevant 
marginal rate of substitution. Thus, both $R^{1}$ and $R^{2}$ are real interest rate variables, defined using the appropriate depreciation rate and price series.

Remember that these simple relations, (3) and (6), are onIy first-order conditions necessary for an optimum. Equations (3) and (6) are not "consumption functions", as they do not relate endogenous decision variables to exogenous forcing variables. As the next section shows, these relations do allow us to estimate the utility function parameters from observed levels of consumption, and thus permit inferences regarding consumer behavior.

These first-order conditions are fully robust to assumptions regarding other markets. In particular, no assumption is necessary regarding the income process or the determination of employment. The labor market can clear continuously, as in neoclassical macromodels, or it can exhibit persistent disequilibrium, as in Keynesian macromodels. In either case, conditions (3) and (6) hold so long as the representative consumer can trade off expenditure today and expenditure tomorrow. 
III. Implementation

The utility function I use to implement the model is the standard constant relative risk aversion utility function. In particular, the following functional forms are used.

(8) $\quad U(C)=\frac{C^{1-\alpha}}{1-\alpha}$ where $\alpha>0$

(9) $V(K)=\frac{\theta K^{1-\beta}}{1-\beta}$ where $\theta>0$ and $\beta>0$

The parameters $\alpha$ and $\beta$ are the Arrow-Pratt measures of relative risk aversion.

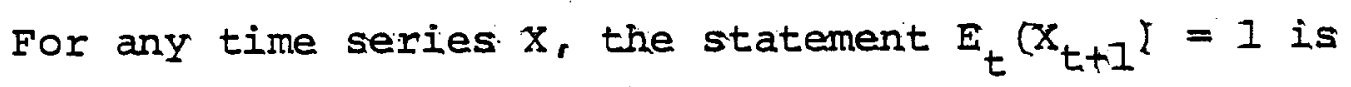
equivalent to the statement $x_{t+1}=1+\varepsilon_{t+1}$. where $E_{t}\left(\varepsilon_{t+1}\right)=0$. We can thus restate the first-order condition (3) and (6) using the realized values of the variables. Using our functional forms (8) and (9), we have the following.

(3') $\frac{R_{t+1}^{1}}{1+\gamma} \frac{C_{t+1}^{-\alpha}}{C_{t}^{-\alpha}}=1+\varepsilon_{t+1}^{1}$

(6') $\frac{R_{t+1}^{2}}{\theta(1+\gamma)} \frac{C_{t+1}^{-\alpha}}{k_{t}^{-\beta}}=1+\varepsilon_{t+1}^{2}$

where $E_{t}\left(\varepsilon_{t+1}^{j}\right)=0$ for $j=1,2$. Thus, the model produces two very simple relations among the realized values of the two choice variables-- $C$ and $\mathrm{K}$--and the two relative price variables-$\mathrm{R}^{1}$ and $\mathrm{R}^{2}$. 
I next linearize the first-order conditions ( $3^{\prime}$ ) and (6'). I take the natural logarithm of both sides of the equations and use the Taylor approximation that $\log \left(1+\varepsilon_{t}^{j}\right) \simeq \varepsilon_{t}^{j}-\frac{1}{2}\left(\varepsilon_{t}^{j}\right)^{2}$. Note that this approximation is exact if the error terms are log-normal. I assume the errors are conditionally homoskedastic. That is, $E_{t}\left[\left(\varepsilon_{t}^{j}\right)^{2}\right]=\sigma_{j}^{2}$ for all $t$. Some simple manipulation produces the following equations.

$$
\begin{aligned}
& \text { (3") } \log \left(C_{t+1} / C_{t}\right)=a_{0}+\frac{1}{\alpha} \log \left(R_{t+1}^{1}\right)+u_{t+1}^{1} \\
& \text { (6") } \log \left(C_{t+1}\right)=b_{0}+\frac{1}{\alpha} \log \left(R_{t+1}^{2}\right)+\frac{\beta}{\alpha} \log \left(k_{t}\right)+u_{t+1}^{2}
\end{aligned}
$$$$
\text { where } \quad a_{0}=\left[\frac{1}{2} \sigma_{1}^{2}-\log (1+\gamma)\right] / \alpha \text {; }
$$$$
b_{0}=\left[\frac{1}{2} \sigma_{2}^{2}-\log (\theta+\theta \gamma)\right] / \alpha
$$$$
u_{t+1}^{j}=\left[\frac{l}{2}\left(\varepsilon_{t+1}^{j}\right)^{2}-\frac{1}{2} \sigma_{j}^{2}-\varepsilon_{t+1}^{j}\right] / \alpha \text {, for } j=1,2 \text {; }
$$

and $E_{t}\left(u_{t+1}^{j}\right)=0$, for $j=1,2$.

These Iinearized first-order conditions are somewhat more tractible and intuitive that ( $\left.3^{\prime}\right)$ and (6'), the equivalent nonlinear versions.

It is useful to examine the linearized first-order conditions (3") and (6") in the special case that the relative price terms, $\mathrm{R}^{1}$ and $\mathrm{R}^{2}$, are constant. Ignoring the constant term, (3") implies that the growth rate of consumption, $\log \left(C_{t+1} / C_{t}\right)$, is white noise, since $E_{t}\left(u_{t+1}^{1}\right)=0$. The level of consumption, $\log \left(c_{t+1}\right)$, is thus a random walk. In addition, no information known at time $t$, apart from $\log \left(c_{t}\right)$, should be useful in forecasting $\log \left(C_{t+1}\right)$. Equivalently, the optimal forecast of $\log \left(C_{t+1}\right)$ is $\log \left(C_{t}\right)$. In an important paper, Hall (1978) first shows these results. Equation (3") is a generalization of Hall's "random walk" theorem. 
The second first-order condition (6") has a similar interpretation. If $R^{2}$ does not vary, then (6") implies that $\log \left(C_{t+I}\right)$ equals a linear function of $\log \left(K_{t}\right)$ plus a white noise error. Again ignoring the constant term, the optimal forecast of $\log \left(C_{t+1}\right)$ is $\frac{\beta}{\alpha} \log \left(k_{t}\right)$. Since by ( $\left.3^{\prime \prime}\right)$ the optimal forecast is also $\log \left(C_{t}\right)$, it follows that $\log \left(K_{t}\right)$ is proportional to $\log \left(C_{t}\right)$. Since $\log \left(C_{t}\right)$ obeys a random walk, $\log \left(K_{t}\right)$ also must obey a random walk. I explore this lastimplication in my 1982 paper, where I conclude the theory fails when confronted with post-war data. That paper, though, assumes a constant real interest rate. All the tests in this paper allow a variable and uncertain real rate of return.

Equation ( $\left.3^{\prime \prime}\right)$ and (6") cannot be estimated using ordinary least squares. We know the error terms $u j t$ are uncorrelated with any variable known at time $t$. But the realized values of $R_{t+1}^{1}$ and $R_{t+1}^{2}$ are not known until time $t+1$. Hence, these variables may be correlated with the error terms, which would lead to inconsistent parameter estimates.

We can produce consistent estimates using the technique of instrumental variables. Since $E_{t}\left(u_{t+1}^{j}\right)=0$, any vector $z_{t}$ known at time $t$ and correlated with $k_{t+1}^{j}$ is a valid set of instruments. Finding such a set $z_{t}$ is certainly not difficult. Below we use alternative instrument lists to ensure the conclusions are robust. 
It is possible to test directly the implication of theory that $E_{t}\left(u_{t+1}^{j}\right)=0$. If we include any variable $x_{t}$ known at $t$ in equation ( $\left.3^{\prime \prime}\right)$ or $\left(6^{\prime \prime}\right)$, the variable $x_{t}$ shoula have a zero coefficient. If the coefficient is statisticaliy significant, then $u_{t+1}^{j}$ is forecastable from known information. contrary to the theory. This test parallels the test of over-identifying restrictions in Hanson and Singleton (1983) and in my 1982 paper with Rotemberg and Sumers.

The approach taken here has an important advantage over the test statistic used in these two previous papers. The only inference we can make from a test statistic is whether a rejection is statistically significant. Yet this is not the primary issue. Any theory is at best an approximation of reality; as such, it is literally false. The primary issue is whether the theory is a good approximation. Thus, we need to know whether a rejection is economically significant. Suppose that $u_{t+1}^{j}$ is forecastable, but only slightly so. We should not conclude on this basis that the theory is invalid. The inclusion of lagged variables in (3") and (6") allows the use of greater judgement. We can examine the coefficients and the standard error of the regression to gauge whether any statistically significant rejection is economically meaningful. 
From the estimates of the utility function parameters, we can compute various relevant elasticities. These elasticities are the best way to guage the implications of the estimates. I compute two kinds of elasticities. The first is a short-run elasticity. Note that all temporary changes in interest rates and prices affect future decisions only through their effect upon the state variable wealth. For a short-run elasticity, this effect is small erough to be ignored. Hence, we assume $\log \left(C_{t+1}\right)$ is unaffected by a temporary change in period $t$ interest rates and prices. From ( $\left.3^{m}\right)$ and $\left(6^{m}\right)$ we know that $(\mathrm{dC} / \mathrm{C}) /\left(\mathrm{dR} \mathrm{R}^{1} / \mathrm{R}^{1}\right)=I / \alpha$ and that $\left(\mathrm{dK} / K I /\left(\mathrm{d} \mathrm{R}^{2} / \mathrm{R}^{2} \mathrm{~L}=I / \beta\right.\right.$. Together with (4) and $(7)$, we can infer the following short-run semi-elasticities and elasticities.

$$
\frac{d C / C}{d P^{c} / P^{c}}=-\frac{1}{\alpha}
$$

$$
\frac{\mathrm{dC} / \mathrm{C}}{\mathrm{di}}=-\frac{(1-\tau)}{\alpha\left(1+(1-\tau) i-\pi^{\mathrm{c}}\right)}
$$

$$
\begin{aligned}
\frac{d K / K}{d i} & =-\frac{(1-\tau)}{B\left(\delta+(1-\tau) i-\pi^{k}\right)} \\
\frac{d K / K}{d P^{k} / P^{k}} & =-\frac{\left(1+(1-\tau)_{i}-\pi^{k}\right)}{B\left(\delta+(1-\tau) i-\pi^{k}\right)}
\end{aligned}
$$

These short-run elasticities are calculated using the estimated parameters and the necessary variables at their historic mean. 
The long-run elasticities are computed assuming $C$ and $K$ are at steady state values. If $Y$ is total expenditure, then $C+\delta K=Y$. This condition, together with equation (6"), produces the following long-run elasticities.

(i4) $\frac{d C / C}{d\left(P^{k} / P^{c}\right) /\left(P^{k} / P^{c}\right)}=\left(\alpha+\beta \frac{C}{\delta K}\right)^{-1}$

(15) $\frac{d K / K}{d\left(P^{k} / P^{c}\right) /\left(P^{k} / P^{c}\right)}=\left(-\alpha \frac{\delta K}{C}-\beta\right)^{-1}$

(16) $\frac{\mathrm{dC} / \mathrm{C}}{\mathrm{dY} / \mathrm{Y}}=\frac{\mathrm{Y}}{\mathrm{K}}\left(\frac{\mathrm{C}}{\mathrm{K}}+\delta \frac{\alpha}{\beta}\right)^{-1}$

$\left(Z T ; \frac{\mathrm{dK} / \mathrm{K}}{\mathrm{dY} / \mathrm{Y}}=\frac{\mathrm{Y}}{\mathrm{K}}\left(\frac{\beta}{\alpha} \frac{\mathrm{C}}{\mathrm{K}}+\delta\right)^{-1}\right.$

These long-run elasticities are also calculated using the parameter estimates and the necessary variables at their historic mean. 
IV. Data

To estimate the model, I use U. S. data from 1950 to 1981. Instead of using quarterly data, as in Hall (1978) and Mankiw (1981), or monthly data, as in Hanson and Singleton (1983), I use data only from the fourth quarter of each year. This procedure, which Hall (1982) also follows, has five justifications. First, the BEA publishes data on the stock of durables only for the end of each calendar year. It is possible to construct a quarterly stock series from the flow data. Bernanke (1982) follows this procedure. Nonetheless, there are clear advantages to using a standard published series.

Second, the use of data at an annual frequency minimizes the problem of seasonal adjustment. Undoubtedly, tastes for consumption are seasonal. The demand for heating oil, for instance, is greater in winter than in sumer. Similarlyr technology makes certain prices seasonal. Certain fruits and vegetables are obvious examples. Ideally, as Miron (1982) discusses, one should encorporate this seasonality into the model. In practice, this often complicates modelling substantially. The standard procedure of using $x-11$ adjusted data has no theoritical justification. This paper avoids the problem of seasonality by the use of onIy fourth quarter data. 
Third, the problem of time averaging also suggests the use of only fourth quarter data. The first-order conditions and (6) apply to $C$ and $K$ at points in time. Observed consumption is measured as an average over an interval. A time average of a stochastic process can have properties very different than the process itself. For example, as Working (1960) shows, the time average of a random walk has serially correlated increments. Thus, the use of contiguous time averages is often not the best way to study the underlying stochastic process. By examining data only from the fourth quarter of each year, the problem of time averaging is greatly reduced.

Fourth, over short intervals, goods labelled nondurable are in fact durable. For example, a pair of shoes, which is classified nondurable in the National Income Accounts, typically lasts longer than three months. Those items called nondurable simply have relatively higher depreciation rates. It is more plausible to believe that shoes fully depreciate over a year than over a month or a:quarter. This suggests the use of an annual rather than a quarterly periodicity. 
The fifth and final justification for the use of only fourth quarter data is based upon the possible illiquidity of consumer durables and upon the costs of adjusting the stock. Mishkin (1976) emphasizes the importance of the illiquidity of consumer durables. Undoubtedly, the resale market for durables is imperfect, largely due to the "Lemons" problem Akerloff (1970) describes. Similarly, Bernanke (1982) stresses the costs of adjusting the stock of durables. Few individuals buy a new car, for example, without time-consuming search and deliberation. This process often delays the actual purchase. These considerations suggest that the stock of durables does not adjust instantly to the desired stock. Nonetheless, over longer periods, the adjustment process is less important. Thus, the model above is likely a better approximation for annual data than for more frequent data.

The variable $C$ is per capita expenditure on nondurables and services in fourth quarter as reported in the National Income and Product Accounts. The variable $\mathrm{k}$ is the per capita net stock of durables at the end of the year. The Bureau of Economic Analysis computes this series. Musgrave (1979) discusses the BEA methodology. The depreciation rate( $\delta$ ) I use is 0.2 , which is consistent with the BEA net stock and flow series.

The interest rate is the three month Treasury bill rate. The rate $i$ is the return from buying a three month $T$-bill in the fourth quarter and reinvesting in T-bills each quarter until the next fourth quarter. I use a constant marginal tax rate $(\tau)$ of 0.3 . 
The price series $P^{k}$ and $P^{c}$ are the NIPA deflators for durables and for nondurables and services, respectively, in the fourth quarter. 


\section{Results}

To estimate equations ( $3^{\prime \prime}$ ) and (6"), . I use two alternative instrument lists. The SHORT list contains only the lagged relative price variable $\log \left(B_{t}^{j}\right)$. The LONG list contains $\log \left(R_{t}^{j}\right)$, $\log \left(R_{t-1}^{j}\right), \log \left(C_{t}\right)$ and $\log \left(C_{t-1}\right)$. Of course, the included exogenous variables, such as $\log \left(\mathrm{K}_{t}\right)$ in $\left(6^{\prime \prime}\right)$, are always included in the first stage equation.

To test the hypothesis that $E_{t}\left(u_{t+1}^{j}\right)=0$, I included disposable: income growth $\log \left(Y_{t} / Y_{t-1}\right)$ in the equations. The alternative hypothesis that some individuals are liquidity constrained suggests a possible correlation between the error term and disposable income. In my 1981 paper, I report that disposable income growth is significant in (3") at the 99 percent level, contrary to the theory. That paper, though, uses contiguous quarter data. As discussed in the last section, the problem of time-averaging can possibly lead to misleading results. In addition, the reduction in the standard error reported in that paper was only four percent. This suggests that, although the forecastability of $u_{t+1}^{1}$ is statistically significant, it may not be economically significant. That is, despite the formal rejection of the overidentifying restrictions, the model may still provide a useful approximation of consumer behavior. 
Table 1 presents estimates of equation (3"). The estimates indicate the utility function parameter $1 / \alpha$ is approximately .37 with a standard error of .33. Equivalently, a is roughly 2.7 with a standard error of 2.4 . In my 1981 paper, I report an estimate of $\alpha$ of 4 . Other studies that examine (3) report a broad range of estimates. Hall (1982) reports that $\alpha$ is about 15, while in my 1982 paper with Rotemberg and summers, we find $\alpha$ well less than one. All the studies report estimates of the theoretically correct sign, which certainly lends support to the model.

The coefficient on disposable income growth is insignificant in ( $3^{\prime \prime)}$. The coefficient is roughly 20 percent lower than the one I report in my 1981 paper and the standard error is larger. It is possible that the inability to reject here is due to the smaller sample size, as the 1981 paper uses quarterly data. On the other hand, the earlier results may be attributable to the use of contiguous time averages. It is difficult to disentangle the various explanations. Yet it appears reasonable to conclude that the model, although likely not exact, provides a good approximation of consumer behavior.

Table 2 presents estimates of equation (6"), the firstorder condition relating the current stocks of consumer durables, future consumption of nondurables and services, and the relative price. The estimate of $1 / \alpha$ is approximately $1 / 3$. This is almost exactly the same as the estimate from equation (3"), a 
Table 1

Estimates of First-order Condition (3")

(1) (2) (3)

(4)

\begin{tabular}{|c|c|c|c|c|c|}
\hline Instrument & List & SHORT & LONG & SHORT & LONG \\
\hline Constant & & $\begin{array}{l}0.023 \\
(.004)\end{array}$ & $\begin{array}{l}0.023 \\
(.004)\end{array}$ & $\begin{array}{l}0.021 \\
(.004)\end{array}$ & $\begin{array}{l}0.021 \\
(.004)\end{array}$ \\
\hline $1 / \alpha$ & $\cdot$ & $\begin{array}{l}0.41 \\
(.35)\end{array}$ & $\begin{array}{l}0.33 \\
(.32)\end{array}$ & $\begin{array}{l}0.38 \\
(.32)\end{array}$ & $\begin{array}{l}0.36 \\
(.32)\end{array}$ \\
\hline Disposable & Income Growth & & & $\begin{array}{l}0.11 \\
(0.12)\end{array}$ & $\begin{array}{l}0.11 \\
(.12)\end{array}$ \\
\hline D.W. & & 1.38 & 1.48 & 1.57 & 1.58 \\
\hline s.e. & & 0.015 & 0.014 & 0.015 & 0.015 \\
\hline
\end{tabular}

Standard errors are in parentheses. 


\section{Table 2}

Estimates of First-Order Condition (6")

(1)

Instrument List

Constant

$1 / \alpha$

$\beta / \alpha$

Disposable Income Growth

D.W.

s.e.

1.10

0.26

0.65
(2)

SHORT

$(.28)$

(.20)

$(.08)$

LONG

1. 28

$(.33)$

0.39

.$(.24)$

0.70

(.09)

(3)

(4)

SHORT

0.99

(.23)

0.19

(.17)

0.61

$(.07)$

0.43

(.28)

1.08

0.78

0.053

0.036

0.038

Standard errors are in parentheses. 
fact that provides strong support for the model. The estimate of $B / \alpha$ is roughly $2 / 3$ and has a small standard error. The data suggest that $\alpha$ is about 3 , and $\beta$ is about 2 . Disposable income growth is again insignificant in (6"), conforming to the theory. On the other hand, the Durbin-Watson statistic is very low, indicating positive serial correlation. This contradicts the theory, since $E_{t}\left[u_{t+1}^{2}\right]=0$ implies $u_{t+1}^{2}$ is serially uncorrelated if $u_{t}^{2}$ is known at time $t$. There are various plausible explanations for this serial correlation. First, the process of adjustment discussed in the last section may lead to this serial correlation. Bernanke's (1982) model suggests it would. Although the use of an annual periodicity may reduce the problem, undoubtedly the adjustment process is not complete each fourth quarter. This is certainly the case when news arrives late in the year. Second, it is possible that tastes for durables relative to nondurables changes throughout the period. This explanation suggests the utility function parameter $\theta$, which is imbedded in the constant term in (6"), is a serially correlated random variable. Third, it is likely that quality changes in durables or nondurables are perceived imperfectly by the Bureau of Economic Analysis. The mistakes in measuring $k_{t}$ or $c_{t}$ undoubtedly persist through time, and thus lead to serially correlated errors in (6"). Fourth, it is likely that simple division by the population does not adequately account for demographic changes. Individuals at 
different stages in life have different consumption patterns. Gradual changes in the age profile of the population, as well as other demographic movements, could explain the serially correlated error. All these explanations suggest that, despite the serial correlation, the model is a useful framework for examining the linkage between interest rates, prices and consumer demand.

Table 3 presents estimates of $\alpha$ and $\beta$ from alternative forms of the first-order conditions ( $3^{\prime \prime}$ ) and (6"). In each of the previous estimated equations, the relative price variable $\mathrm{R}^{j}$ is placed on the right hand side of the equation. Although this normalization may be more natural, it is also econometrically correct to rewrite $\left(3^{\prime \prime}\right)$ and $\left(6^{\prime \prime}\right)$ with $\log \left(R^{j}\right)$ as the left hand side variable. Both normalizations produce consistent estimates under the null hypothesis that the model is correct. In a finite sample, the estimates may be different. For the SHORT instrument list, the normalization is irrelevant, since the equation is exactly identified. A comparison of column 3.1 with column 1.1, and column 3.3 with column 2.1, verifies this fact. As is shown in columns 3.2 and 3.4 , the estimates using the IONG instrument list do change with this alternative normalization. Yet the signs of $\alpha$ and $\beta$ are still correct. In addition, although the alternative estimates are smaller, they are not greatly different when compared to the standard errors. 
Table 3

Estimates from Alternative Forms
(1)
(2)
(3)
(4)

Left Hand

Side Variable $\log \left(R^{1}\right) \quad \log \left(R^{1}\right) \quad \log \left(R^{2}\right) \quad \log \left(R^{2}\right) \quad \log \left(R^{2} / R^{1}\right)$

Instrument List SHORT LONG SHORT LONG OLS

Constant

$-0.06$

$-0.04$

$(.04)$

$(.02)$

$-4.2$

(2.2)

$-1.9$

$-1.9$

2.42

$(2.02)$

1.58

3.79

$(.5)$

(.5)

$\alpha$

(1.24)

(2.98)

0.72

0.78

(.70)

$\beta$

2.46

0.77

0.80

(1.64)

$(.40)$

(.38)

D.W.

1.38

1.15

0.88

1. 28

1.39

s.e.

0.036

0.026

0.16

0.12

0.10

Standard errors are in parentheses. 
The last column in Table 3 presents estimates from a hybrid of (3") and (6"). If we solve these two equations to eliminate $\log \left(C_{t+1}\right)$, we obtain a relation between $\log \left(R_{t+1}^{2} / R_{t+1}^{1}\right), \log \left(C_{t}\right)$ and $\log \left(\mathrm{K}_{t}\right)$. We can estimate this relation with ordinary least squares, since $\log \left(C_{t}\right)$ and $\log \left(K_{t}\right)$ are known at time $t$ and hence uncorrelated with the error term. The estimates of $\alpha$ and $\beta$ from this equation again have the correct sign, lending further support to the model, although they are also smaller than those presented in Tables 1 and 2 .

Table 4 presents various elasticities for $\alpha=1.5$ and $\beta=1$, which appear reasonable parameter estimates. Also presented are the elasticities for other plausible parameter values. The short-run interest semi-elasticities are particularly striking. A one percentage point rise in the interest rate reduces consumption of nondurables and services by .5 percent. It reduces the stock of durables by 3.4 percent. Since the stock of consumer durables is roughly four times the annual flow, a one percentage point rise in the real interest rate reduces annual expenditure on durables by about 13.6 percent. 
rable 4

Elasticities for Various Utility Function Parameters

Short Run

$\frac{d c / c}{d i}$

$\mathrm{dC} / \mathrm{C}$

$\overline{d p^{c} / p^{c}}$

$\frac{d k / K}{d i}$

$\frac{d k / K}{d p^{k} / p^{k}}$

$\alpha=3$
$\beta=2$

$-0.24$

$-0.33$

$-1.71$

$-2.46$

$-4.92$

0.11

$-.84$

0.95

1.42

$\mathrm{d} \mathrm{K} / \mathrm{K}$

$\overline{d Y / Y}$
0.05

$-0.42$

0.95

1. 42 $\alpha=.8$

$B=.8$

$-.88$

$-1.25$

$-4.28$

$-6.15$

0.14

$-1.11$

1.00

1.00 
V. Conclusion

This paper examines the linkage between interest rates and consumption both of durables and of nondurables and services. The model presented here accords well with U.S. postwar data. The estimated coefficients have the correct sign, and are well within the range of.estimates from previous studies. In addition, when the same structural parameter is estimated in different equations, the two estimates are very close. These findings suggest that the model is a good first approximation of consumer behavior.

The estimates indicate that consumer expenditure on durables is very responsive to changes in the real interest rate. This finding is consistent with casual observation. For example, it is widely believed that high real interest rates caused the recent recession. Between 1979 and 1982, inflation fell from 11.7 percent to 4.1 percent. At the same time, the three month Treasury bill rate rose from 10.0 percent to 10.7 percent. Consumer spending during this recession was strong, probably because of the large personal tax cuts. Consumption of nondurables and services rose by 4.9 percent during these three years. Expenditure on durables, though, fell by 5.8 percent. This pattern is precisely what one would expect from 
the policy mix. Personal tax cuts bolstered consumers' expectations as to their permanent income. But restrictive monetary policy lead to high real interest rates, which increased the relative price of holding durables relative to consuming nondurables and services. It is not surprising that the auto industry suffered particularly high.unemployment during this economic downturn.

Although the model explains the data well, there are various generalizations future research should pursue. The strongest restriction imposed in this paper is the form of the utility function. The various additive separability assumptions could be relaxed. In particular, future work should pay closer attention to the role of adjustment costs. A model that took account of the adjustment process would be better suited for examining the effects of shorter term fluctuations in the real interest rate. The model presented here provides only a first step for understanding the connection between interest rates and consumer expenditure. 


\section{References}

Akerloff, George, 1970 - The Market for 'Lemons': Qualitative Uncertainty and the Market Mechanism, Quarterly Journal of Economics, August.

Bernanke, Ben, 1982 - Adjustment Costs, Durables and Aggregate Consumption, NBER Working Paper No. 1038.

Grossman, Sanford J. and Robert Shiller, 1981 - The Determinants of the Variability of Stock Market Prices, American Economic Review 7\%, No. 2, pp. 222-227.

Hall, Robert E., 1978 - Stochastic Implications of the Life Cycle-Permanent Income Hypothesis: Theory and Evidence, Journal of Political Economy 86, No. 6, pp. 971-987.

Hall, Robert E., 1982 - Intertemporal Substitution in Consumption, NBER Working Paper.

Hanson, Lars Peter, and Renneth J. Singleton, 1983 Stochastic Consumption, Risk Aversion and the Temporal

Behavior of Stock Market Returns, forthcoming in the Journal of Political Economy.

Lucas, Robert E., Jr., 1976 - Econometric Policy Evaluation: A Critique, Journal of Monetary Economics Supplement, Carnegie-Rochester Conference Series, Volume 1.

Mankiw, N. Gregory, 1981 - The Permanent Income Hypothesis and the Real Interest Rate, Economics Letters 7, pp. 307-311.

Mankiw, N. Gregory, 1982 - Hall's Consumption Hypothesis and Durable Goods, Journal of Monetary Economics.

Mankiw, N. Gregory, Julio J. Rotemberg and Lawrence H. Summers, 1982, Intertemporal Substitution in Macroeconomics, NBER Working Paper No. 898 (forthcoming in the Quarterly Journal of Economics).

Miron, Jeffrey A., 1982 - The Seasonality of Economic Time Series, MIT.

Mishkin, Frederic, 1976 - "Illiquidity, Consumer Durable Expenditure and Monetary Policy," American Economic Review 6.6, pp. 642-654.

Musgrave, John C., 1979 - Durable Goods Owned by Consumers in the United States, 1925-77, Survey of Current Business, March. 
References - Continued

Runkle, David, 1982 - Liquidity Constraints and the Permanent Income Hypothesis: Evidence from Panel Data, MIT.

Shapiro, Matthew, 1983 - The Permanent Income Hypothesis and the Real Interest Rate: Evidence from Panel Data, MIT.

Shiller, Robert, 1982 - Consumption, Asset Markets and

Macroeconomic Fluctuations, Journal of Monetary Economics Supplement, Caṛnegie-Rochester Conference Series, Volume 17.

Summers, Lawrence H.., 1982 - Tax Policy, The Rate of Return, and Savings, NBER Working Paper No. 995.

Working, Holbrook, 1960 - Note on the Correlation of First Differences of Averages in a Random Chain, Econometrica No. 4. 